\title{
Article \\ The Operation Analysis of the Innovative MainBox Food Storage Device
}

\author{
Magdalena Wróbel-Jędrzejewska *(D) and Elżbieta Polak
}

check for

updates

Citation: Wróbel-Jędrzejewska, M.; Polak, E. The Operation Analysis of the Innovative MainBox Food Storage Device. Appl. Sci. 2021, 11, 7682. https://doi.org/10.3390/app11167682

Academic Editor: Cédric Delattre

Received: 16 July 2021

Accepted: 19 August 2021

Published: 20 August 2021

Publisher's Note: MDPI stays neutral with regard to jurisdictional claims in published maps and institutional affiliations.

Copyright: (c) 2021 by the authors. Licensee MDPI, Basel, Switzerland. This article is an open access article distributed under the terms and conditions of the Creative Commons Attribution (CC BY) license (https:// creativecommons.org/licenses/by/ $4.0 /)$.
Agriculture and Food Biotechnology—State Research Institute, 02-532 Warsaw, Poland; elzbieta.polak@ibprs.pl * Correspondence: magdalena.jedrzejewska@ibprs.pl

\begin{abstract}
The development and construction of a prototype device (food parcel locker), consisting of small cooling and freezing chambers (boxes) ensuring temperature conditions $\left(+5 \mathrm{C}\right.$ or $\left.-18{ }^{\circ} \mathrm{C}\right)$, enabling food storage were carried out. The innovative solutions have been introduced in the MainBox device: the appropriate construction of the device (materials, cooling installation), properly functioning systems (control of chillers, security, temperature monitoring), and propane as refrigerant (high energy efficiency, low global warming potential). The risk of explosion has been eliminated by closing of the cooling installation and reducing of propane amount. The refrigeration unit has been adapted to work in external conditions by installing additional elements (pressure switches for compressor protection and for condensing pressure control). In real conditions, the operation of the innovative MainBox food storage device allowing the receipt of food products without having to wait for a supplier was verified. The temperature distribution in all chambers of the cooling and freezing module was investigated using a thermal imaging camera and a temperature monitoring system. The correct operation of MainBox devices was verified during their loading with food products that require specific temperature conditions during storage.
\end{abstract}

Keywords: cold chain; e-shopping; food parcel locker; food storage; propane

\section{Introduction}

Ensuring food safety and quality is a particular challenge in the face of population growth [1,2]. The procedures for maintaining the stable conditions under which chilled or frozen food products must be stored are referred to as cold chain $[3,4]$. On the other hand, reducing food waste, especially in households, is possible through rational purchasing of products [5]. Currently, new food distribution channels are sought that would facilitate its delivery in appropriate storage conditions (temperature) and at a convenient time [6]. The identification of trends in sustainable delivery on e-commerce market in cities from the perspective of various stakeholders is a complex issue [7]. E-grocery is developing into a frequent and prominent form of online shopping. Home delivery of food and groceries is associated with fewer trips to physical grocery stores and reduced car use on these trips [8]. There is a need for e-retailers and other companies participating in the e-commerce supply chain to develop a variety of strategies [9]. The consumer behavioral research on computer human interactions and implications for transport policy confirmed that the effects of convenience, privacy security, and reliability on customers' decisions are fully depended on value and transaction costs, which were verified by theoretical research on self-service in technologies of sale [10]. Food storage equipment enables convenient distribution of products ordered online. However, a prerequisite is the maintenance of the appropriate temperature for individual assortments. In the case of chilled and frozen products, deviation from the required temperature in any of the links in the cold chain may result in lower quality or product spoilage and pose a health risk [11].

The e-commerce growth has increased the complexity of logistics operations in urban environments, i.e., delivery drones and ground autonomous delivery devices [12] and 
mobile warehouses [13] are under consideration. Ensuring proper cooling conditions requires designing cooling devices with optimal parameters, which will also be environmentally friendly $[14,15]$. When constructing them, it is necessary to take into account national and international legal acts that impose actions aimed at limiting environmental threats, including the ozone hole [16] and the greenhouse effect [17]. The use of synthetic refrigerants (f-gases) is limited and, therefore, the natural refrigerant use is dedicated to the newly designed devices.

Research work was carried out which enabled the construction of an innovative MainBox device, ensuring temperature conditions $\left(+5^{\circ} \mathrm{C}\right.$ or $\left.-18^{\circ} \mathrm{C}\right)$. This product is intended to store food under certain temperature conditions and enable the collection of ordered food products by customers without having to wait for the supplier. The device structure has been developed, taking into account the appropriate materials, type of sealing, chamber size, construction of the chamber door, necessary elements of the cooling and condensate drainage system, as well as automated control of temperature. The natural refrigerant propane is used in the cooling system [18]. Based on its properties, innovative solutions have been designed for, among others, cooling installation, temperature monitoring and regulation, security system, and ventilation of food storage chambers. There is an increased interest in the use of hydrocarbons in refrigeration, e.g., propane (R600a) in mixtures [19-21], isobutane (R290) in domestic refrigeration [22], and mixed R290/R600a in the compressors [23].

In general, supply chains and logistics have been disrupted due to the pandemic situation [13]. The developed device is a response to the current society need. It is the right solution for providing food to consumers in the difficult reality of the sanitary regime, caused by the epidemiological threat of COVID-19 (coronavirus) [24]. Currently, the development potential of this form of food trade has increased enormously, and the crucial point is ensuring optimal storage conditions. On the other hand, it is the dissemination of pro-environmental solutions related to the natural refrigerant use and action aimed at climate protection by reducing the direct emission of greenhouse gases which translates into a minimalization of the carbon footprint (CF) of this device $[25,26]$.

The article describes the experimental work performed to verify the correct operation of the cooling and freezing prototypes of devices (MainBox), which are the subject of the project. The purpose of this study was to investigate the operation of the innovative MainBox device, in real conditions, for food storage in optimal temperature.

\section{Research Methods}

\subsection{Test Stand}

The technological challenge was to develop and design prototype external bodies for refrigeration and freezing modules. The role of the body was to provide protection of the refrigeration system elements from the influence of external factors, as well as from their destruction. The work has been carried out in the following steps: selection of an insulator, sealant, and lining material for the inside of the box; the construction of the cabinet bodies, taking into account individual components (their location); execution of the bodies (filled with a specific insulator) with the required physical properties. The development of the systems for cooling and freezing modules, as well as the execution and verification of their operation took place in the following stages: first, the cooling systems (including condensate drainage) with automation and control and the electrical installations for the cooling and freezing modules were designed and executed; next, their operation was verified in model conditions and in real environmental conditions. Prototypes of the bodies of modules (cooling and freezing) of the MainBox device were built of stainless steel with space inside for cooling and other necessary installations, including measuring instrumentation and operating the customer's access system to a given box (Figure 1). Cooling and electrical installations with measuring and control instrumentation were located in the upper part of MainBox body. The module consisted of 5 chambers (boxes) for food storage. Each box was opened at the front with a separate door. 
Requirements were developed that had to be met by the designed unit:

- Constructional assumptions:

- The rear wall of the MainBox had to be removable (service and maintenance requirements).

- Leveling of thermal bridges with polyamide joints.

- Optimization of installation sites for electronics and refrigeration in boxes and cutting out appropriate holes and securing them.

- Requirements determination for explosion-proof electrical box. Optimal size and location behind the evaporator, among other things, in the electrical box had to fit additional controllers, relays.

Temperature monitoring assumptions:

- Placement of temperature sensors at the outlet was planned to control the performance of the cool system. If the temperature was not low enough: possibility to activate controlled forced cooling.

- Optimization of the temperature sensor placement was carried out including additional temperature gauges to monitor and record the temperature on each shelf.

- $\quad$ Equipment operation assumptions:

- The use of a defrost heater to heat the cold box in the winter.

- The air inlet and outlet places on the shelves were planned to be located-air blades allowing for regulation of the air inlet in the side wall. Implementation of the air controllers with insulating material (styrodur).

- Smart wire to the door to prevent freezing of the door seal.
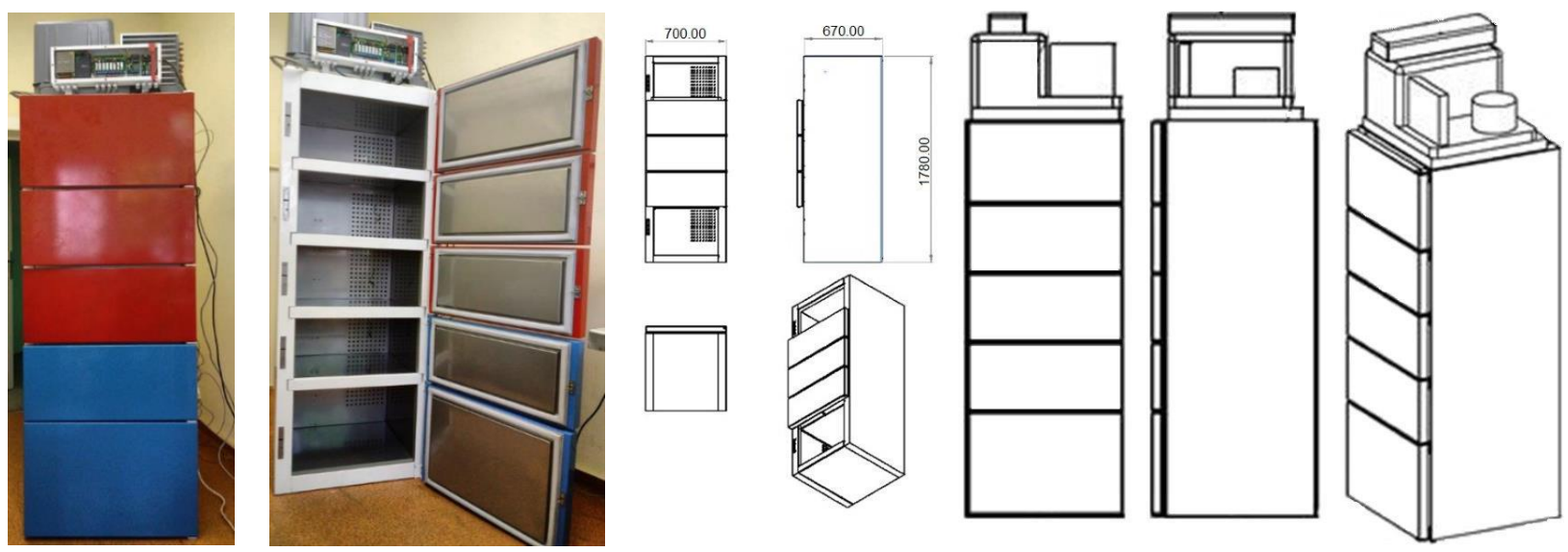

Figure 1. MainBox device with cooling systems cooperating with automation and control (picture, scheme with dimensions in $\mathrm{mm})$.

A temperature control system, security systems, and automation and cooling systems control have been designed and manufactured. Design innovations in the MainBox construction have been carried out in the following steps.

1. The MainBox used compact air cooling devices (monoblock) with the necessary certification provided by the manufacturer. A refrigeration unit designed for indoor refrigeration furniture was used to work in outdoor conditions, which forced the use of additional elements in the refrigeration unit itself, which were not normally installed:

- High and low pressure compressor protection pressure switches.

- High pressure switch to control the condensing pressure by switching the condenser fan on and off (necessary at low outdoor temperature).

2. The temperature in cooling chambers was ensured by blowing cold air which, after being heated in the chambers, went back through the ventilation duct to the cooling 
device located above the chambers and was cooled in the evaporator. The heat removed from the air was disposed of in a condenser cooled by external air.

3. Due to the fact that, in the chambers, a temperature of $+5^{\circ} \mathrm{C}$ had to be ensured and the whole system will operate at outdoor temperatures from $-20{ }^{\circ} \mathrm{C}$ to $+35^{\circ} \mathrm{C}$, an additional electric heater was used:

- An additional electric heater on the evaporator with a power of $400 \mathrm{~W}$, which, in combination with the standard defrosting heater with a power of $230 \mathrm{~W}$, ensured heating of the chambers at negative outside temperatures. Both heaters were controlled by a thermostat located in the electrical box based on the temperature reading of the air returning to the refrigeration unit.

- Temperature control in individual boxes was correlated with the return air temperature to the chiller, because the air returned to the chiller through a common return duct. This was averaged over all boxes. Based on this temperature reading, the module's local controller turned the chiller on and off. Temperature sensors have been installed at all air outlets from the boxes to prevent a temperature rise in individual boxes. If the return air temperature from any box exceeded the upper setpoint, then the master controller forced the cooling of the entire module regardless of the temperature reading in the common return duct. Once the temperature was reduced to the setpoint, the master controller removed the forced chiller operation signal and the unit returned to local controller operation based on the return air temperature.

- Adequate circulation of cooled air was ensured by the appropriate amount of cooled air flowing into individual boxes to obtain the same temperature in each of the return air streams with an accuracy of $\pm 1{ }^{\circ} \mathrm{C}$.

- In order to eliminate the risk of the door freezing to the casing due to the appearance of water or frost on its edge, an appropriate heating installation was installed in the place of door contact.

4. The refrigeration unit was filled with the natural refrigerant (propane- $-\mathrm{R} 290$ ), due to its following advantages over typical synthetic refrigerants such as R134a, R452a, and R404a:

- GWP-greenhouse effect potential for propane is 3, where for R134a it is = 1430, for $\mathrm{R} 452 \mathrm{a}=2141$, and for $\mathrm{R} 404 \mathrm{a}=3922$.

- High energy efficiency (lower energy consumption with similar cooling capacity) -for a cooling capacity of $434 \mathrm{~W}$ (evaporation $-10^{\circ} \mathrm{C}$ and condensation $+50{ }^{\circ} \mathrm{C}$ ), the electrical power of the unit with propane is $154 \mathrm{~W}$-for R134a, it is $208 \mathrm{~W}$ (efficiency $457 \mathrm{~W}$ ), and for R452a, it is $239 \mathrm{~W}$ (efficiency $467 \mathrm{~W}$ ).

5. Propane flammability is the disadvantage, but this problem has been eliminated by:

- Using the propane advantage of a high specific mass cooling capacity of $290 \mathrm{~kJ} / \mathrm{kg}$ and for which the amount of refrigerant in the system was only $90 \mathrm{~g}$ (this exempted fire protection) — for R134a, it was $150 \mathrm{~kJ} / \mathrm{kg}$ and $240 \mathrm{~g}$.

- Hermetically sealing the refrigeration system. This meant that all connections were soldered. The system did not have a service valve for possible refrigerant recovery and filling in case of repair work. The service pipe was clamped and also soldered. Special tools must be used for repair work.

6. The unit complies with fire and safety regulations. This solution increased fire safety in the event of a refrigerant leak. It also prevented the refrigerant from accumulating in one place, because the density of propane is higher than that of air. The boxes were cooled down by blowing the cooled air from the evaporator through a ventilation duct located at the rear of the module and through air supply openings in the rear walls of the boxes, while the side walls of the boxes were equipped with air deflectors.

7. The doors of individual boxes were opened by lifting the lock of the door of a given box after reading the correct code provided by the supplier or recipient of goods. Door opening should last as short as possible. For this purpose, the module was 
equipped with a door opening sound signal, which reminded the person opening the door that it was not closed. After a specified time (e.g., $15 \mathrm{~s}$ ), the intensity of this signal changed. If the door still did not close, the technical service was notified.

In order to verify the correctness of the MainBox operation in real conditions, food sets were prepared for their loading. Food products that require specific temperature conditions during storage were included. The chambers of the prototype refrigeration unit were filled with products from the following groups (dairy products, cold cuts, meat, ready meals: fruit/vegetables). On the other hand, the prototype freezing device contained: ice cream, frozen vegetables/fruit, and culinary products. Products stored in refrigeration and freezing conditions were packed in two types of packaging: biodegradable foil packaging and cardboard packaging.

\subsection{Testing Temperatures in Prototype Equipment}

The conditions for storing products in prototype cooling and freezing devices were monitored. For this purpose, the optimal arrangement of temperature sensors in each MainBox chamber and the system for the continuous recording of these parameters were designed. The diagram of the device with the location of these sensors and every box internal dimensions is shown in Figure 2. In each box, the sensor was placed in the upper right corner, $15 \mathrm{~cm}$ from the top edge and $12 \mathrm{~cm}$ from the side edge. Monitoring the temperature inside the MainBox was possible through the developed and installed temperature recording system. The temperature was recorded for every $2 \mathrm{~min}$ through $48 \mathrm{~h}$ in 5 iterations.

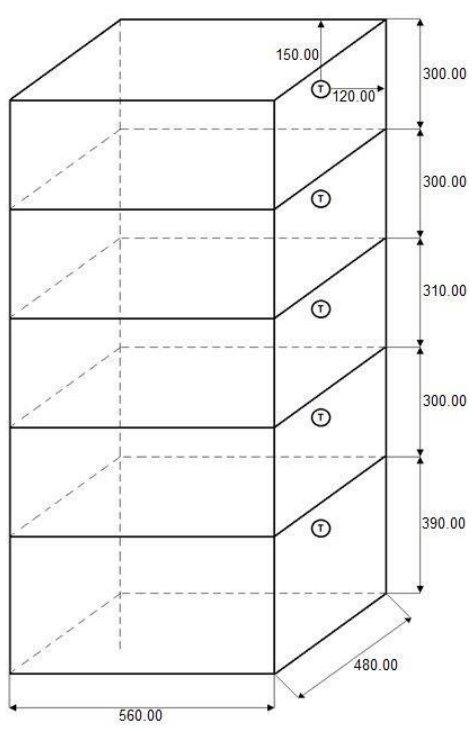

Figure 2. Arrangement of temperature sensors inside the device chambers, and dimensions in $\mathrm{mm}$.

\subsection{Thermal Imaging Tests on Prototype Devices}

The operation of the cooling and freezing modules was tested in real weather conditions in the city of Lodz, Poland in July 2019, and the temperatures during this period are shown in Figure 3.

The temperature distribution, heat transfer, and tightness in individual boxes of the innovative MainBox device were examined, depending on the type of stored products. These studies were carried out using thermal imaging techniques. For the analysis and monitoring of temperatures, a FLIR T1020 $28^{\circ}$ thermal imaging camera with a $1024 \times 768$ pixel detector was used, characterized by the following parameters: sensitivity $20 \mathrm{mK}\left(<0.02{ }^{\circ} \mathrm{C}\right)$, measurement accuracy $\pm 1{ }^{\circ} \mathrm{C}$ or $\pm 1 \%$, measurement range $40{ }^{\circ} \mathrm{C}$ up to $+2000{ }^{\circ} \mathrm{C}$, and spatial resolution for $28^{\circ}$ lens. The study used its own measurement methodology in the measuring range of the thermal imaging camera from $-40{ }^{\circ} \mathrm{C}$ to $+150{ }^{\circ} \mathrm{C}$ with the use of the HB-250 tape for identification and measurement of the emissivity coefficients [27]. 


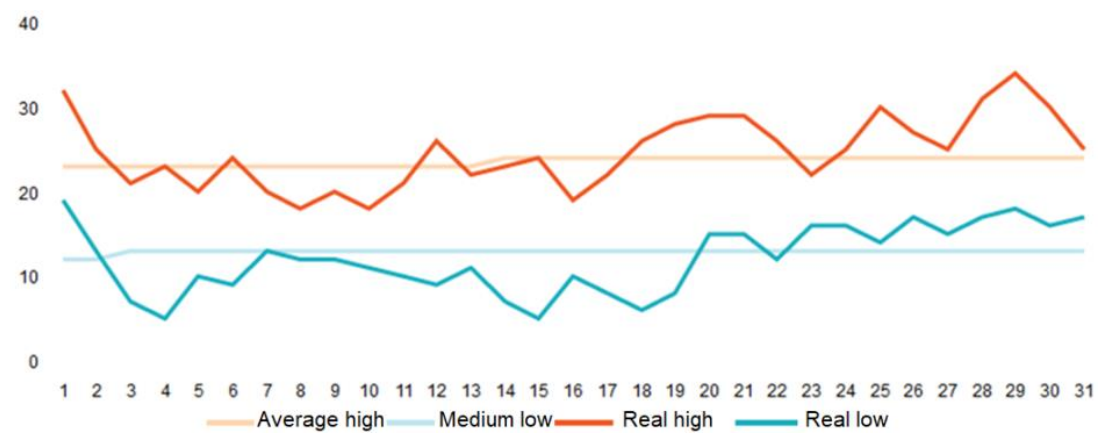

Figure 3. Temperature conditions in Lodz in July 2019.

\subsection{Refrigerant Characteristics}

For the designed device, a propane (R290) refrigeration system was selected. The properties of this factor, in the light of the regulations and the plans to amend the Regulation (EU) 517/2014 on fluorinated greenhouse gases [28], were a key argument for use in commercial refrigeration furniture, including the designed MainBox. As of 2020, all refrigeration equipment may only be filled with low GWP refrigerant. Such requirements are met by propane with a GWP $=3$ index and zero ozone depletion potential $(\mathrm{ODP}=0)$, thus it has no harmful effect on the environment [29]. At the same time, propane as an environmentally friendly medium is an efficient refrigerant (it has similar properties to R22, difluorochloromethane, which is now withdrawn from use).

Propane is characterized by high energy efficiency, good volumetric capacity, and has a large compressor operating range, when compared to the HFC refrigerants (currently withdrawn from applications). Its use is limited by flammability and explosiveness. It is classified in the A3 safety group. These features limited its use to small refrigeration systems, e.g., air conditioners installed outside buildings, and hermetic commercial equipment and chilled water units. It was assumed that the filling in the chiller would not exceed $150 \mathrm{~g}$ of propane in order to ensure the safety of the designed device [30]. In addition, a special electrical equipment was also used to work in an explosive atmosphere. The MainBox is dedicated to operate in the open air, which minimized the risk of an explosive atmosphere in the event of refrigerant leak.

The cooling capacity of each module was determined, taking into account the storage temperatures of $+5^{\circ} \mathrm{C}$ and $-18{ }^{\circ} \mathrm{C}$, equipment capacity, insulation, as well as location (temperature conditions inside and outside). The total capacity of the chambers in the module was estimated at approximately $350 \mathrm{~L}\left(0.35 \mathrm{~m}^{3}\right)$. Commercial refrigeration furniture most often had an aggregate with a capacity, respectively, for the cooling system approximately $200-250 \mathrm{~W}$, and for the freezing, approximately $230-410 \mathrm{~W}$. As part of the research, on the basis of electric power consumption, the following outputs were determined:

- For a $298 \mathrm{~W}$ cooling module, at the following temperatures: evaporation $-5{ }^{\circ} \mathrm{C}$, chamber $+2{ }^{\circ} \mathrm{C}$, and ambient $+40^{\circ} \mathrm{C}$.

- For the $410 \mathrm{~W}$ freezing module, at the following temperatures: evaporation $-25^{\circ} \mathrm{C}$, chamber $-18^{\circ} \mathrm{C}$, and ambient $+40^{\circ} \mathrm{C}$.

The cooling installation was adapted by designing appropriate safeguards (e.g., pressure switch, electric heater) to different environmental conditions (air temperatures ranging from $-20^{\circ} \mathrm{C}$ to $+35^{\circ} \mathrm{C}$ ), as the food storage modules will be installed outside the shop buildings. A pressure switch (a sensor showing a differential pressure) kept the pressure within the specified range on the condenser. When the pressure dropped below the set value, the fan was turned off, and when the pressure exceeded the set value, it was turned on. When the ambient temperature reached negative values, it was necessary to use an additional electric heater, which in the case of a cooling module, prevented the temperature in the chambers from dropping below $+5{ }^{\circ} \mathrm{C}$, and it helped to maintain the optimal temperature for storing products. 
When performing thermovision tests and interpreting thermograms, the criterion of temperature difference of more than $10^{\circ} \mathrm{C}$ between a given area of the contact surface or electrical device with increased temperature and its surroundings was adopted as the condition indicating improper operation of a given component. However, for the assessment of the construction of objects (e.g., insulation), the significant temperature difference was about $2{ }^{\circ} \mathrm{C}$. Special attention was paid to the temperature range assigned to individual thermograms, because the isotherm colors of one thermogram did not correspond to the colors and temperatures of the other thermograms. An important factor in the thermograms' interpretation was the type of surface and material from which the component was made. This was due to the fact that the emission factor of the measured surface was different. Therefore, for example, some painted components may have a different color on the thermogram despite the same temperature.

\section{Results and Discussion}

\subsection{Temperature Monitoring of Prototype Equipment}

Monitoring of the temperature inside the MainBox was possible with the developed and installed system of its recording with the optimal arrangement of sensors. The measured temperatures of individual boxes of the cooling and freezing modules (numbering of chambers from the top of the module, as shown in Figure 2) were within the ranges given in Table 1 . Temperature readings were with the accuracy $\pm 0.1^{\circ} \mathrm{C}$. An exemplary record of the internal temperatures monitoring in the chambers of the cooling and freezing modules recorded temperature amplitude of approximately $3{ }^{\circ} \mathrm{C}$ and $6{ }^{\circ} \mathrm{C}$, respectively (Figures 4 and 5). Thus, the designed and manufactured prototype devices with the necessary installations made it possible to maintain appropriate temperature conditions in the empty chambers.

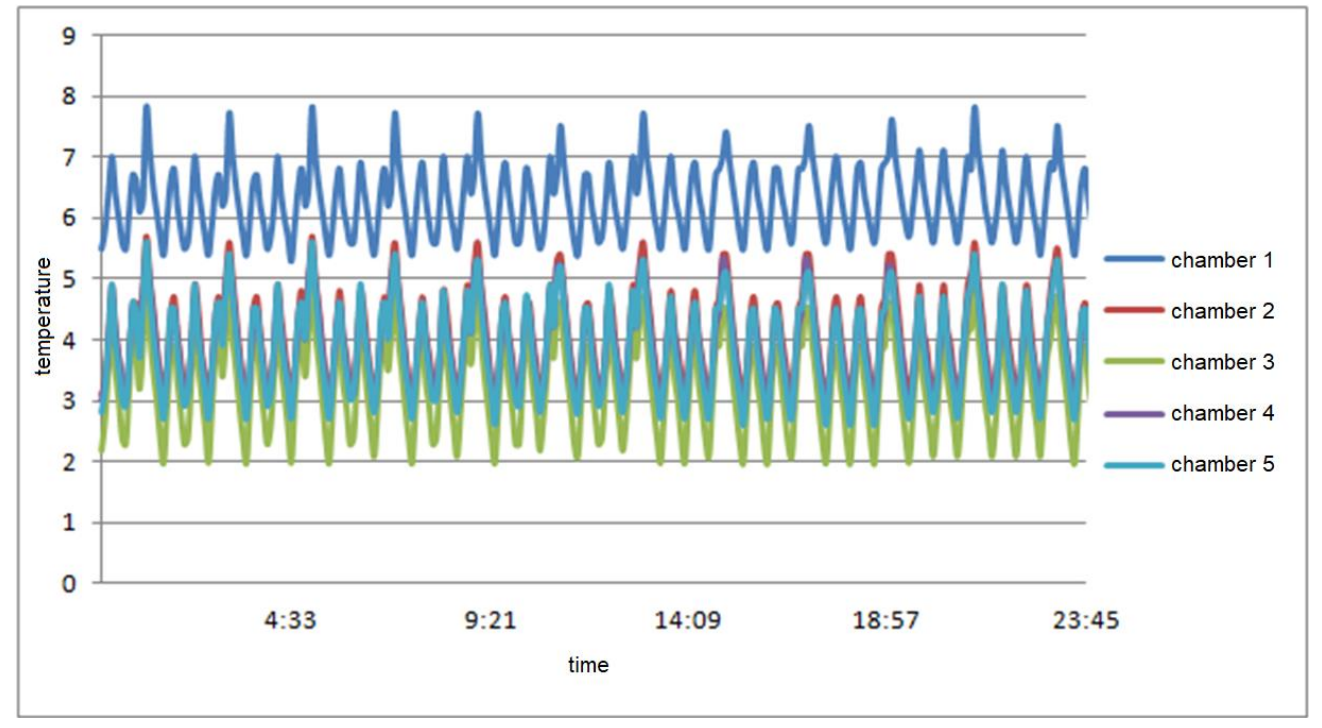

Figure 4. Temperature distribution in the cooling module chambers. 


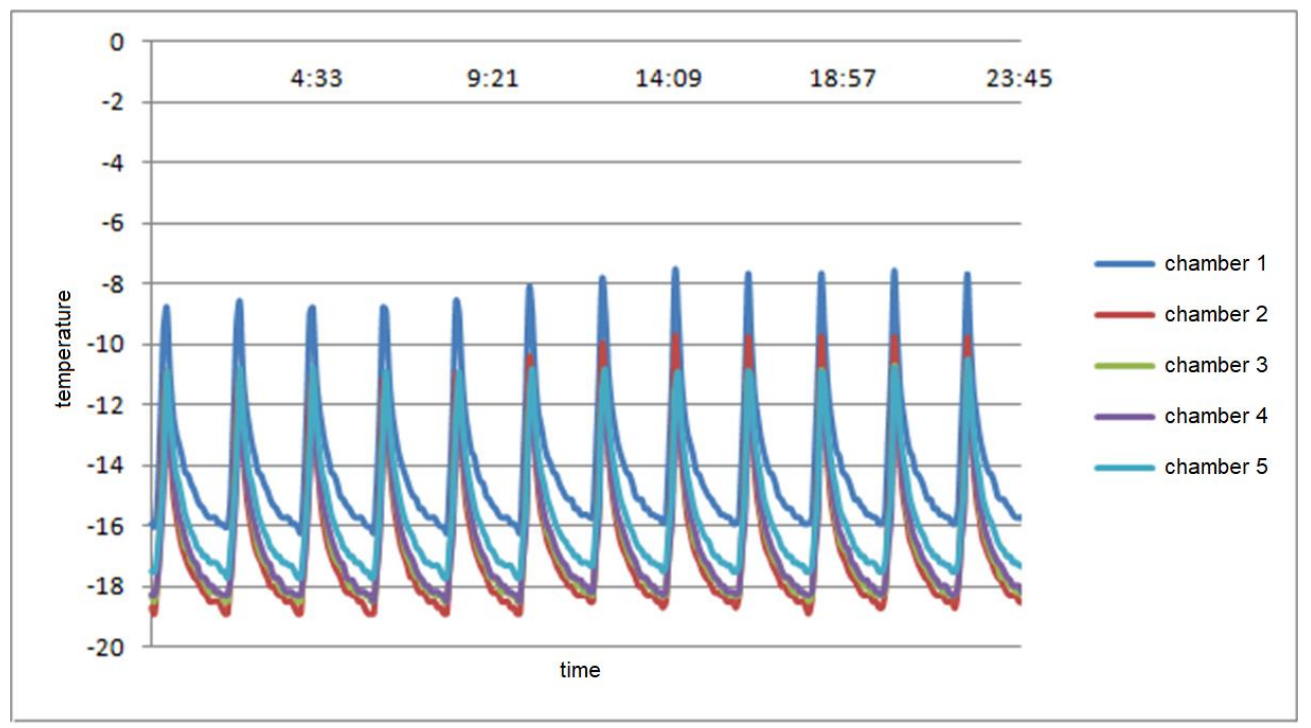

Figure 5. Temperature distribution in the freezing module chambers.

Table 1. Temperature of individual chambers of the cooling and freezing module.

\begin{tabular}{ccc}
\hline \multirow{2}{*}{ Chamber/Box No. } & Cooling Module $\left({ }^{\circ} \mathbf{C}\right)$ & Freezing Module $\left({ }^{\circ} \mathbf{C}\right)$ \\
\cline { 2 - 3 } & \multicolumn{2}{c}{$\min \div \mathbf{m a x}$} \\
\hline 1 & $6.0 \div 7.4$ & $-16.4 \div-14.4$ \\
2 & $3.1 \div 6.9$ & $-19.5 \div-16.5$ \\
3 & $1.8 \div 4.9$ & $-19.0 \div-16.0$ \\
4 & $2.6 \div 5.8$ & $-18.0 \div-13.7$ \\
5 & $2.4 \div 6.1$ & $-17.7 \div-16.0$ \\
\hline
\end{tabular}

The analysis of the storage conditions of food products in all chambers of the cooling and freezing module was carried out over a period of approximately $48 \mathrm{~h}$, starting from the loading with food products to emptying them. In both prototypes, optimal storage conditions were maintained in each box during loading (Tables 2 and 3). Smaller temperature fluctuations occurred in the chambers during the unloading of products, both in the cooling boxes (Figure 6) and in the freezing boxes (Figure 7). In the case of the freezing module, temperature differences of approximately $7^{\circ} \mathrm{C}$ were identified. The minimum freezer storage ranges (below $-18^{\circ} \mathrm{C}$ ) were achieved. The temperature data showed that relatively stable temperatures were maintained for $48 \mathrm{~h}$ during storage.

Table 2. Temperatures in individual cooling module boxes during product loading.

\begin{tabular}{ccc}
\hline Chamber/Box No. & $\begin{array}{r}\text { Temperature Inside the } \\
\text { Empty Box }\left({ }^{\circ} \text { C) }\right.\end{array}$ & $\begin{array}{c}\text { Temperature Inside the Box } \\
\text { Immediately after Loading with the } \\
\text { Products }\left({ }^{\circ} \text { C) }\right.\end{array}$ \\
\hline 1 & 7.9 & 11.2 \\
2 & 5.4 & 8.6 \\
3 & 4.6 & 7.8 \\
4 & 5.6 & 9.3 \\
5 & 5.6 & 9.5 \\
\hline
\end{tabular}


Table 3. Temperatures in individual freezing module boxes during product loading.

\begin{tabular}{ccc}
\hline Chamber/Box No. & $\begin{array}{r}\text { Temperature Inside the } \\
\text { Empty box }\left({ }^{\circ} \mathbf{C}\right)\end{array}$ & $\begin{array}{r}\text { Temperature Inside the Box } \\
\text { Immediately after Loading with the } \\
\text { Products }\left({ }^{\circ} \mathbf{C}\right)\end{array}$ \\
\hline 1 & -16.4 & -14.4 \\
2 & -19.5 & -16.5 \\
3 & -19.0 & -16.0 \\
4 & -18.0 & -13.7 \\
5 & -17.7 & -16.0 \\
\hline
\end{tabular}
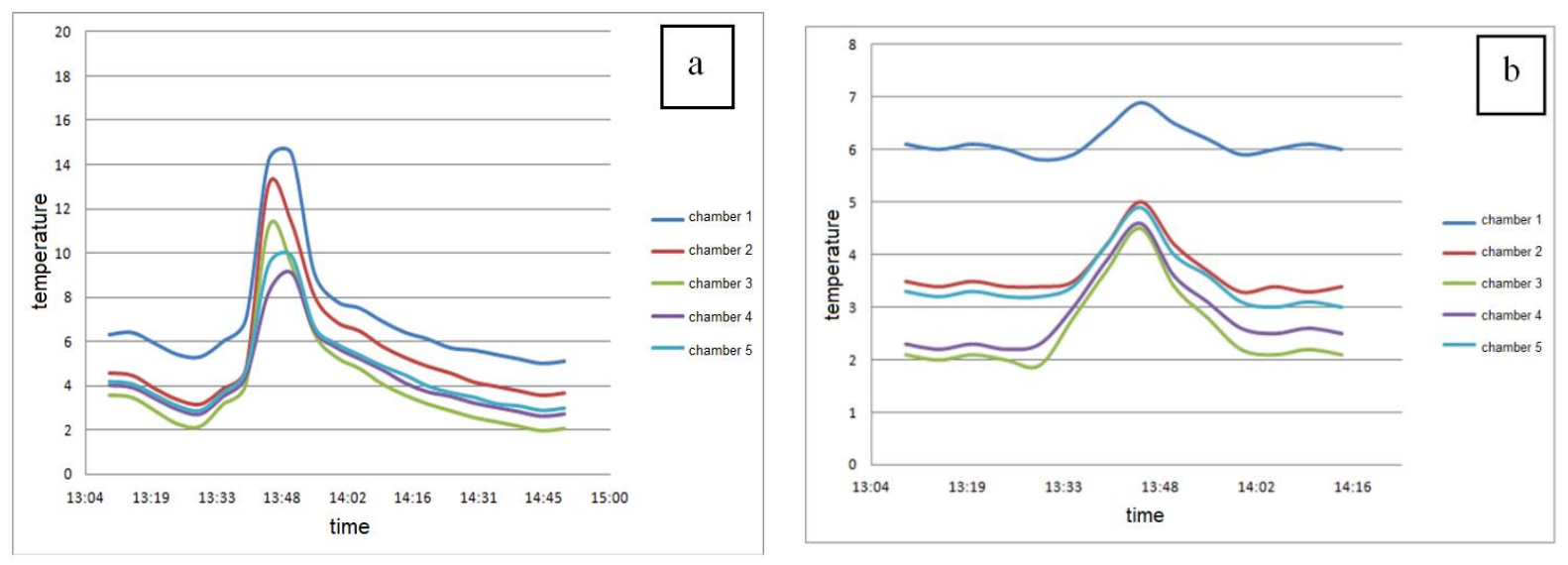

Figure 6. Temperature monitoring in the boxes of the cooling module during insertion of food products (a) or removal of food products $(\mathbf{b})$.
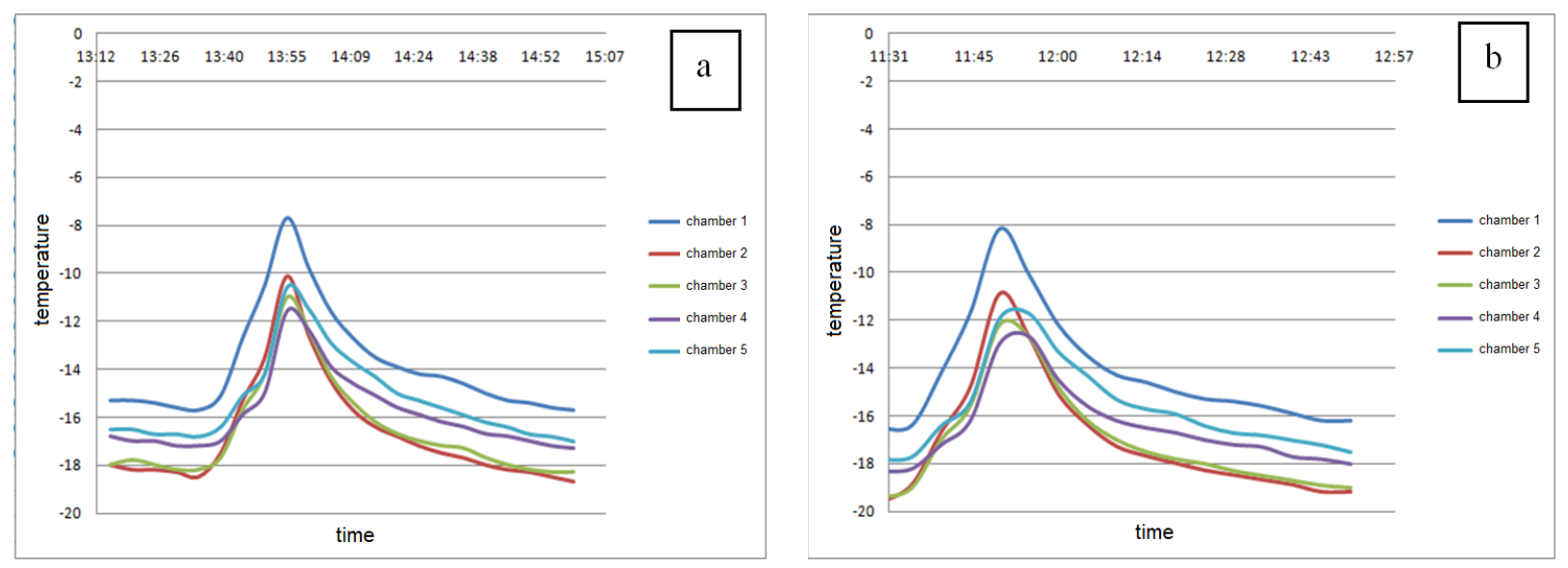

Figure 7. Temperature monitoring in the freezing module boxes during insertion of food products (a) or removal of food products $(\mathbf{b})$.

To identify thermal anomalies for all filled chambers of the cooling and freezing module immediately after storage, thermal imaging studies were carried out. The exemplary thermograms for chamber 2 in these modules are shown in Figures 8 and 9. The obtained results confirmed that the temperatures were kept at the required level in accordance with the specifications of the project.

Based on the analysis of temperatures, indications of stored frozen and chilled food, and thermovision studies, it was found that the temperatures in all module chambers were acceptable, both for empty chambers and with maximum filling. The modules constructed as part of the project were tested in real conditions. Ensuring optimal temperature condi- 
tions inside the chambers was possible with a properly functioning system for controlling cooling units.

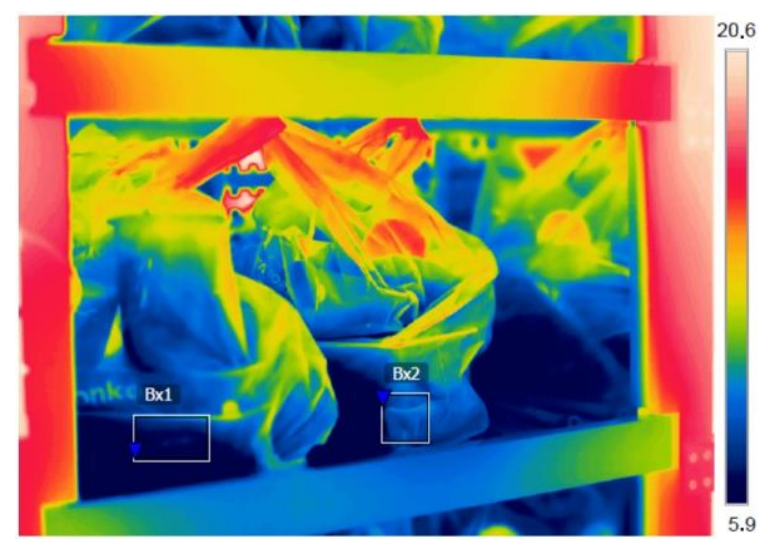

$\operatorname{Bx} 14.1^{\circ} \mathrm{C}$
Bx2 $6.1^{\circ} \mathrm{C}$

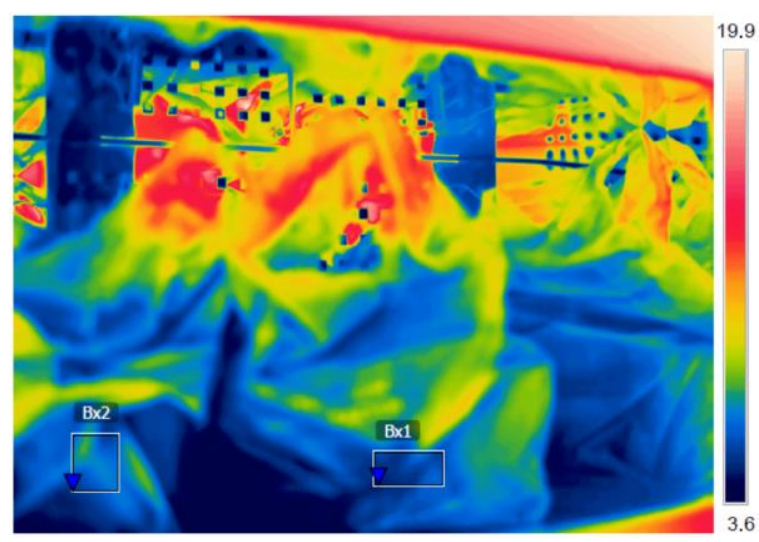

$\mathrm{B} \times 14.7^{\circ} \mathrm{C}$
$\mathrm{B} \times 25.2^{\circ} \mathrm{C}$

Figure 8. Thermograms for the filled chamber 2 of the cooling module immediately after storage.

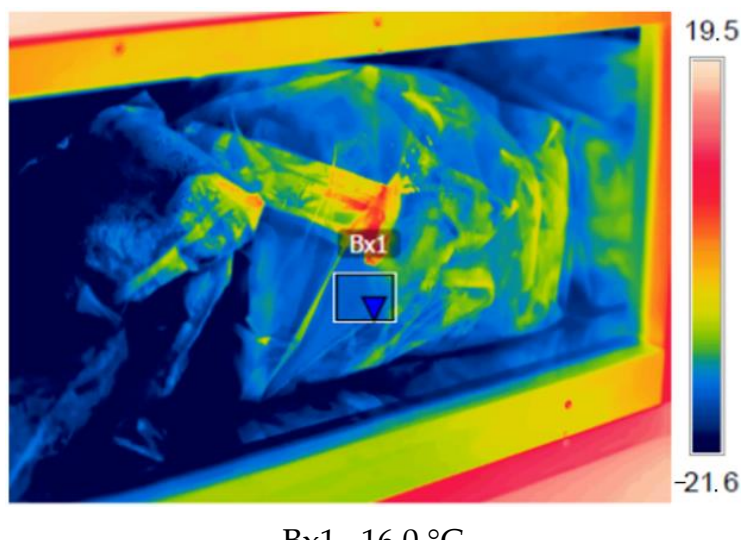

$\mathrm{Bx} 1-16.0^{\circ} \mathrm{C}$

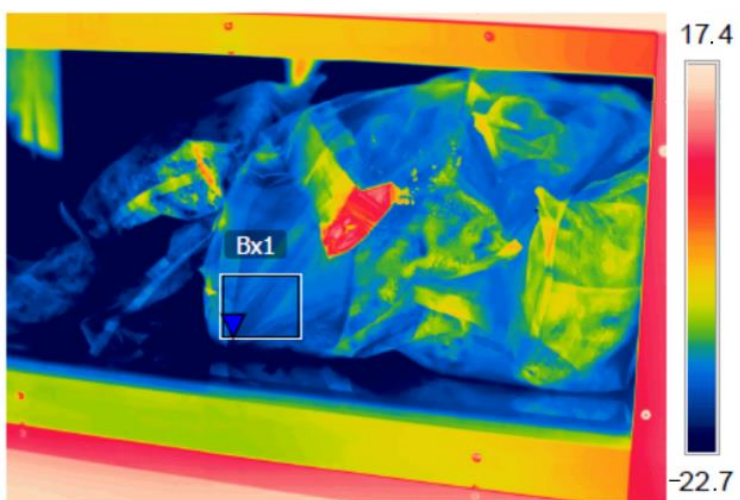

$\mathrm{Bx} 1-18.5^{\circ} \mathrm{C}$

Figure 9. Thermograms for the filled chamber 2 of the freezing module immediately after storage.

The heat exchange process (the condenser fan operation) was regulated by a high pressure switch. When the value of $16 \pm 4$ bar was exceeded, the fan was turned on; otherwise, it was turned off. In the modules, the controller also protected the chiller. If the evaporator return air temperature dropped by more than $2{ }^{\circ} \mathrm{C}$ from the set point, the low temperature alarm was triggered after $20 \mathrm{~min}$. A protection system against too high temperatures has also been developed and installed in the modules. If the value increased by more than $5^{\circ} \mathrm{C}$ (compared to the proper value), the alarm was also triggered after $20 \mathrm{~min}$. Moreover, the refrigeration unit was protected against too low or too high pressure of the refrigerant by appropriate pressure switches. They were plugged in series into the compressor power supply electric circuit and, in the event of overpressure, they switched off the compressor power supply. It was restored when the pressure returned to the recommended value plus or minus the differential.

To protect the products stored in the boxes of the cooling module against freezing when the external temperature dropped below $0^{\circ} \mathrm{C}$, all boxes were heated with an additional heater.

The analysis of the influence of negative ambient temperature on the operation of cooling and freezing modules was performed. It was not possible to verify their operation in real winter weather conditions, due to the duration of the research. However, when analyzing the lowest temperatures in Poland in the last five years [31], it was concluded that they did not reach $-30{ }^{\circ} \mathrm{C}$ over longer periods. 
For products stored in the freezing module chambers, the minus outside temperature poses no risk of damage. In the developed solution, the cooling system was turned off (there was no need for it to operate), and the storage temperature in the chambers was maintained at the level required for frozen products (approximately $-18^{\circ} \mathrm{C}$ ). However, when the temperature in the chamber increased, the refrigeration unit was restarted. This was possible with the installation of an appropriate compressor oil sump heater.

On the other hand, products stored in the refrigeration module chambers, when exposed to negative ambient temperature, may be damaged. In order to prevent the temperature inside the boxes of the refrigerated cabinet from lowering (to negative values), heaters with a power of $500 \mathrm{~W}$ were used. This value was sufficient, even at the outside temperature of $-30^{\circ} \mathrm{C}$ (which, as can be seen from the charts, was not achieved in Poland even in the coldest months). Even if such a temperature occurred, these are short-term periods and will not cause undesirable effects. The device had a cooling power of $410 \mathrm{~W}$, and ensured trouble-free achievement of a sufficiently low temperature with a difference of $\Delta \mathrm{T}=30^{\circ} \mathrm{C}$. The heaters had a power of $500 \mathrm{~W}$; thus, by analogy, they ensured a temperature increase of even $\Delta \mathrm{T}=35^{\circ} \mathrm{C}$. The applied solutions allowed to guarantee the proper operation of the cooling and freezing modules in the analyzed environmental conditions.

\subsection{Tightness Monitoring of Prototype Cooling Chambers}

The tightness control of cooling and freezing modules filled with food products packed in collective packaging was carried out using the FLIR T1020 thermal imaging camera (Figures 10 and 11). The maximum time the products remained in the chambers until they were picked up by customers was set at $24 \mathrm{~h}$. During the tests, the recorded ambient temperature was $23^{\circ} \mathrm{C}$.

In the prototype of the cooling and freezing module (Figures 10 and 11), minimum temperatures in certain areas were identified, which indicated the presence of thermal bridges and insufficient insulation. These were due to improperly placed gaskets, both on the hinge and lock sides. Thermal bridges were found at the edge of contact between the shelves and the plane of the chamber door. The identified irregularities were eliminated in the prototype device. The places requiring elaboration in the construction of the cooling module have been shown in the thermograms:

- Structure leakage - chamber door side wall of the module, causing thermal bridges and insulation leakage between the module and the monoblock (see minimum point Bx1 on Figure 12),

- Thermal bridges on the side wall of the module and insulation leakage between the module and the monoblock (see minimum point Bx1 on Figure 13).

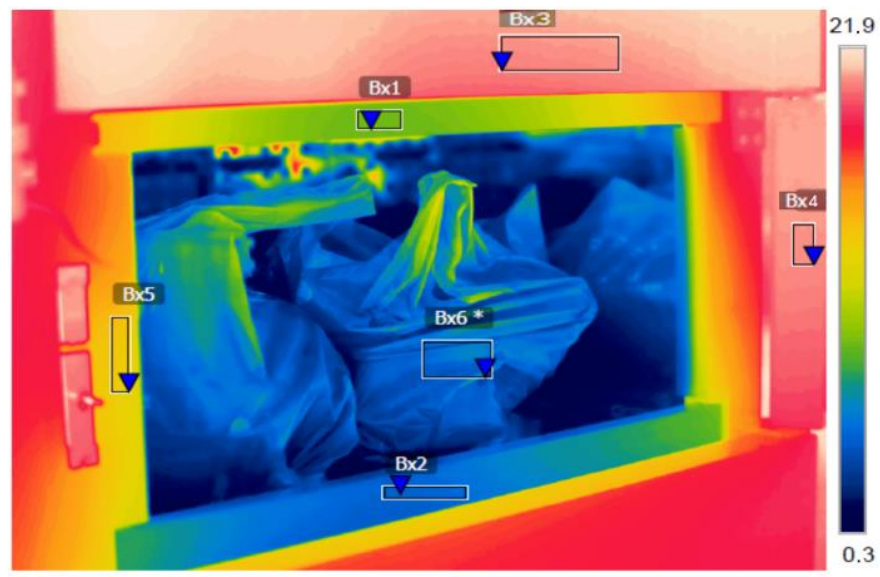

Bx1 $9.1^{\circ} \mathrm{C}$

Bx2 $4.9^{\circ} \mathrm{C}$

Bx3 $20.3^{\circ} \mathrm{C}$

Bx4 $20.5^{\circ} \mathrm{C}$

Bx5 $13.4{ }^{\circ} \mathrm{C}$

$\mathrm{B} \times 6^{*} 4.8^{\circ} \mathrm{C}$

Figure 10. Thermogram for the loaded chamber 2 of the cooling module. 


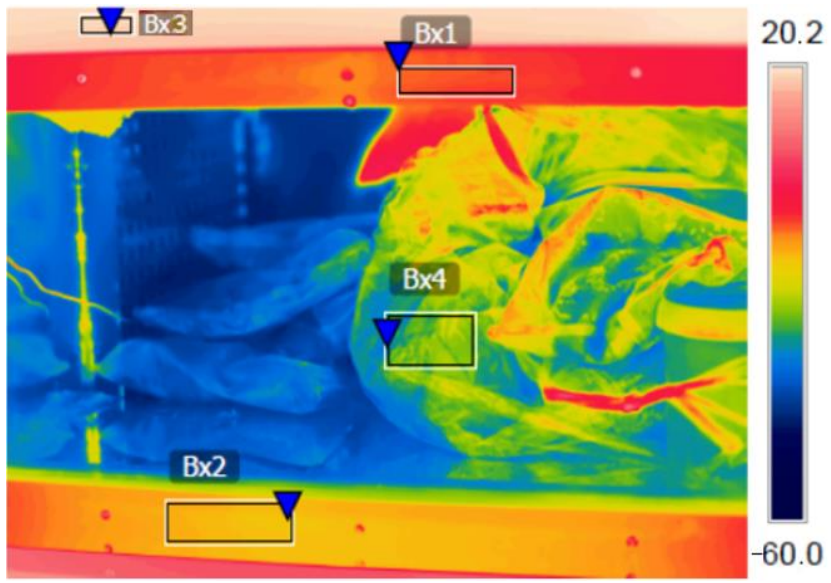

\author{
$\mathrm{Bx} 1-0.2{ }^{\circ} \mathrm{C}$ \\ Bx2 $-4.4{ }^{\circ} \mathrm{C}$ \\ $\mathrm{B} \times 318.9^{\circ} \mathrm{C}$
}

$\mathrm{B} \times 4-20.5^{\circ} \mathrm{C}$

Figure 11. Thermogram for the loaded chamber 2 of the freezing module.

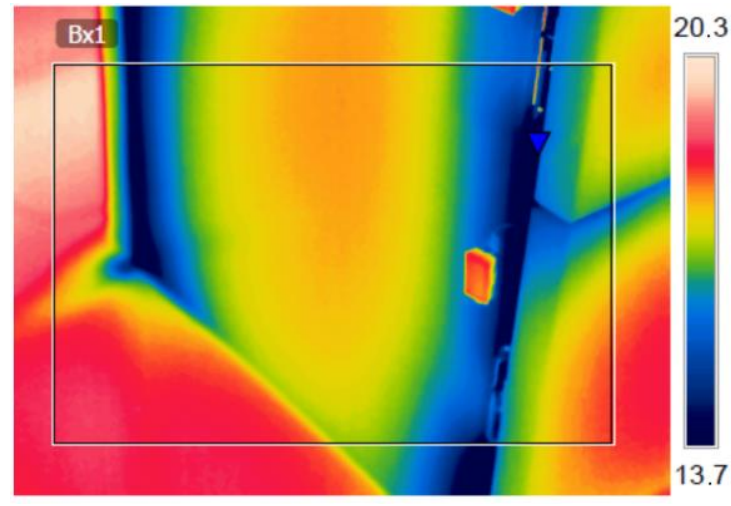

Bx1 $11.7^{\circ} \mathrm{C}$

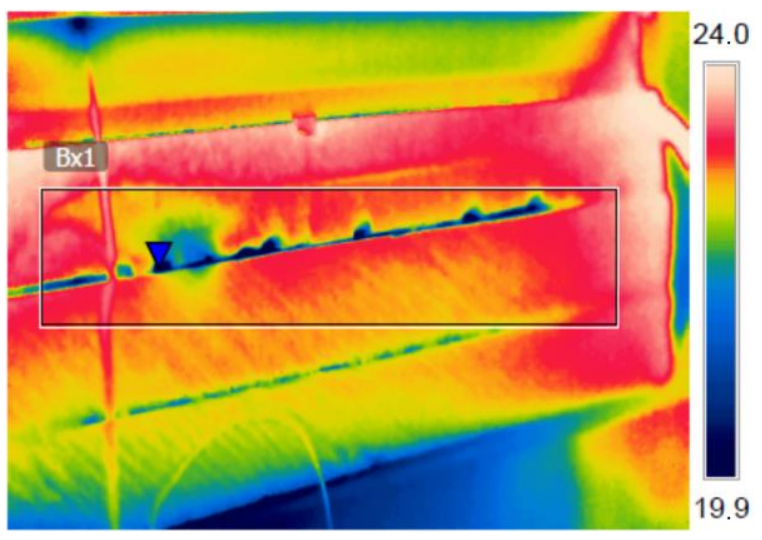

Bx1 $15.1^{\circ} \mathrm{C}$

Figure 12. Thermograms of the cooling module-structure leakage: chamber door side wall of the module, caused thermal bridges; insulation leakage between the module and the monoblock.

The temperatures of the stored food in the prototype module, after $24 \mathrm{~h}$ of storage, were acceptable (Figures 10 and 11). Thermovision made it possible to show the places where modules were modified (leaks removed), the energy losses were lower, which translated into financial savings during operation and benefited for the natural environment (lower amount of carbon dioxide emissions). Such action made the developed innovative devices more attractive for food distributors, as appropriate storage conditions were ensured with lower operating costs.

The structural imperfections shown on the example of the cooling module were also identified in the freezing module, where the leakage phenomenon was even more noticeable, which was visible in the exemplary thermograms of the freezing module cabinet in Figure 13.

The MainBox device has been implemented. The first device was tested in Poznan, Poland. The manufacturer of the device ensures that the tests were successful, hence the decision to go with an offer of cooperation to grocery store chains, drugstores, or catering companies. 

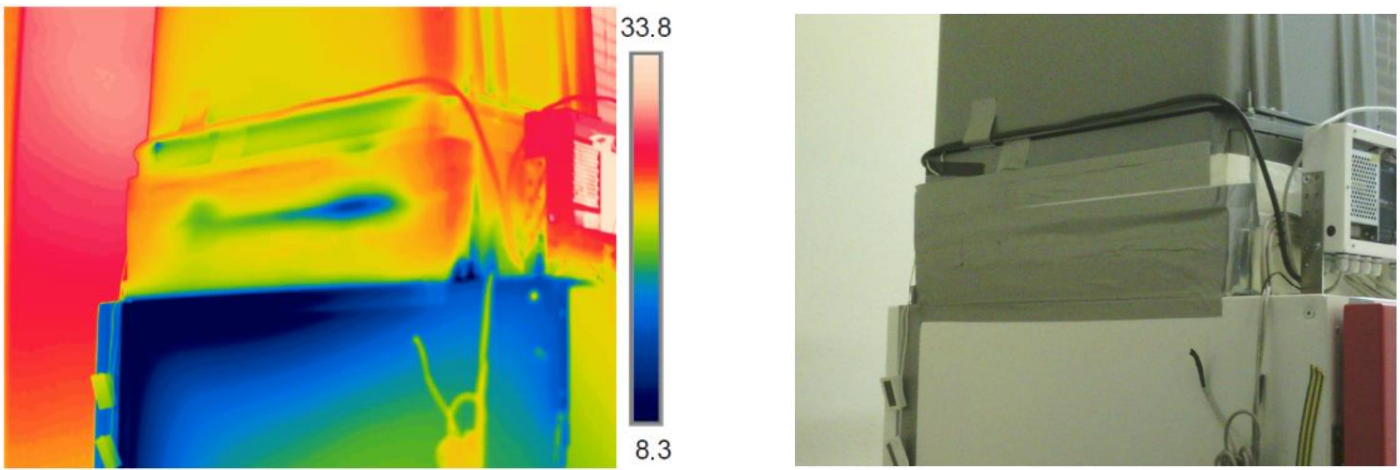

$\operatorname{Bx} 10.3^{\circ} \mathrm{C}$

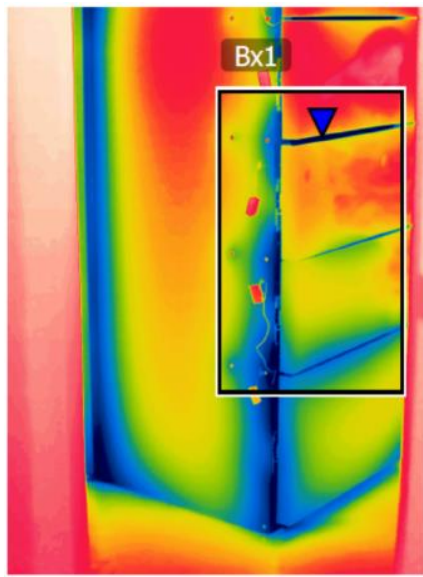

23.5

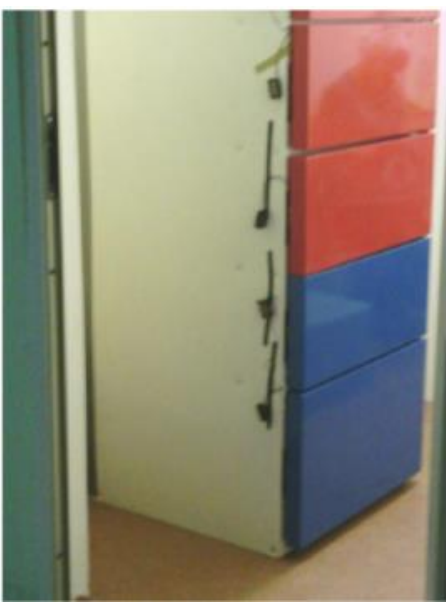

$\operatorname{Bx} 10.3^{\circ} \mathrm{C}$

Figure 13. Thermograms of the freezing module-thermal bridges on the side wall of the module and insulation caused leakage between the module and the monoblock.

\section{Conclusions}

MainBox prototype units were designed and built. The solution is optimized in terms of greenhouse gas emissions by maximizing energy efficiency and using natural refrigerant in refrigeration and freezing systems. The innovative food box solution is a breakthrough in the food market, as it has a huge commercial potential while reducing the negative effects of civilization (food waste) and climate change. The device uses a working fluid with low greenhouse effect creation potential; this will enable practical implementation of legislative requirements (national and international) regarding the so-called greenhouse gases. The following innovative solutions have been introduced in the MainBox device:

- The refrigeration unit was adapted to work in external conditions by installing additional elements (pressure switches for protecting compressor, pressure switch for condensing pressure control).

- $\quad$ Temperature control in individual boxes correlated with temperature of return air to cooling unit was designed and heating of chambers was ensured.

- Optimum access to the boxes was ensured.

- $\quad$ Propane as a natural refrigerant was used (high energy efficiency, low GWP), eliminating its amount and sealing the device, thus reducing the risk of explosion (the device met the requirements of fire and safety regulations).

The correct MainBox device operating parameters were maintained with a properly functioning system for the cooling units control and a temperature monitoring system.

At the beginning, the identified structural imperfections in the modules made it possible to react quickly and performed modifications to the insulation that would ensure appropriate storage conditions and reduce the need for cold. Summarizing the conducted 
thermovision examinations, it was found that there were no anomalies in the operation of the equipment, no anomalies of the MainBox insulation, and no anomalies related to overheating of wires, excessive load on electrical connections. Thermal imaging studies of the temperature of food stored for $24 \mathrm{~h}$ in refrigeration and freezer furniture showed optimal temperatures of these products.

Thermal imaging tests and temperature monitoring have confirmed that the designed and manufactured food storage devices allowed maintaining optimal temperature conditions inside the chambers. MainBox is a device that allowed to safely receive food products at any time, which was a specific need during an epidemic time. Rational use of energy in the agro-food industry through optimization of thermal processes translated into ensuring food safety throughout the entire cold chain.

The developed new product MainBox is an advanced food device that enables remote ordering and collection at any time of food products, previously delivered by a selected supplier. MainBox customers can easily and quickly make current purchases without unnecessary storage at home and pick up the ordered purchases (e.g., on their way home from work), preventing their expiration, spoilage and, consequently, wasting. MainBox will contribute to rational food management.

\section{Patent}

Patent Application P.437818 Use of Refrigerant as a Cold Carrier in Refrigeration and Freezing Equipment (10 May 2021).

Author Contributions: Conceptualization, M.W.-J.; Data curation, M.W.-J.; Formal analysis, M.W.-J.; Funding acquisition, E.P.; Investigation, M.W.-J.; Methodology, M.W.-J.; Resources, M.W.-J.; Software, M.W.-J.; Validation, E.P.; Visualization, M.W.-J.; Writing—original draft, M.W.-J.; Writing—review \& editing, E.P. All authors have read and agreed to the published version of the manuscript.

Funding: The work was carried out at the Department of Refrigeration Technology and Technique IBPRS in cooperation within a research project entitled "Conducting research and development works at D\&K Technology, aimed at developing an innovative MainBox product, enabling the receipt of food products without waiting for the supplier", financed by the Wielkopolska Regional Operational Program for 2014-2020. Action 1.2.

Institutional Review Board Statement: Not applicable.

Informed Consent Statement: Not applicable.

Data Availability Statement: Not applicable.

Conflicts of Interest: The authors declare that they have no known competing financial interests or personal relationships that could have appeared to influence the work reported in this paper.

\section{References}

1. Formoso, G.; Pipino, C.; Baldassarre, M.P.A.; Del Boccio, P.; Zucchelli, M.; D’Alessandro, N.; Tonucci, L.; Cichelli, A.; Pandolfi, A.; Di Pietro, N. An Italian innovative small-scale approach to promote the conscious consumption of healthy food. Appl. Sci. 2020, 10, 5678. [CrossRef]

2. Evansa, K.S.; Teisl, M.F.; Lando, A.M.; Liu, S.T. Risk perceptions and food-handling practices in the home. Food Policy 2020, 95, 101939. [CrossRef]

3. Zhang, X.; Lam, J.S.L.; Iris, Ç. Cold chain shipping mode choice with environmental and financial perspectives. Transp. Res. Part D Transp. Environ. 2020, 87, 102537. [CrossRef]

4. Sarkar, B.; Omair, M.; Choi, S.-B. A multi-objective optimization of energy, economic, and carbon emission in a production model under sustainable supply chain management. Appl. Sci. 2018, 8, 1744. [CrossRef]

5. Carson, J.K.; East, A.R. The cold chain in New Zealand-A review. Int. J. Refrig. 2018, 87, 185-192. [CrossRef]

6. Talbot, L.; Purnell, G.; James, S.J.; James, C. Operating temperatures of supermarket frozen retail display cabinets. Int. J. Refrig. 2020, 117, 81-93. [CrossRef]

7. Kiba-Janiak, M.; Marcinkowski, J.; Jagoda, A.; Skowrońska, A. Sustainable last mile delivery on e-commerce market in cities from the perspective of various stakeholders. Literature review. Sustain. Cities Soc. 2021, 71, 102984. [CrossRef]

8. Bjørgen, A.; Bjerkan, K.Y.; Hjelkrem, O.A. E-groceries: Sustainable last mile distribution in city planning. Res. Transp. Econ. 2021, 87, 100805. [CrossRef] 
9. Janjevic, M.; Winkenbach, M. Characterizing urban last-mile distribution strategies in mature and emerging e-commerce markets. Transp. Res. Part A Policy Pract. 2020, 133, 164-196. [CrossRef]

10. Yuen, K.F.; Wang, X.; Ma, F.; Wong, Y.D. The determinants of customers' intention to use smart lockers for last-mile deliveries. J. Retail. Consum. Serv. 2019, 49, 316-326. [CrossRef]

11. Wu, J.-Y.; Hsiao, H.-I. Food quality and safety risk diagnosis in the food cold chain through failure mode and effect analysis. Food Control 2021, 120, 107501. [CrossRef]

12. Lemardele, C.; Estrada, M.; Pages, L.; Bachofner, M. Potentialities of drones and ground autonomous delivery devices for last-mile logistics. Transp. Res. Part E Logist. Transp. Rev. 2021, 149, 102325. [CrossRef]

13. Srinivas, S.S.; Marathe, R.R. Moving towards "mobile warehouse": Last-mile logistics during COVID-19 and beyond. Transp. Res. Interdisc. Persp. 2021, 10, 100339.

14. Leng, L.; Zhang, J.; Zhang, C.; Zhao, Y.; Wang, W.; Li, G. Decomposition-based hyperheuristic approaches for the bi-objective cold chain considering environmental effects. Comput. Oper. Res. 2020, 123, 105043. [CrossRef]

15. Castillo-González, E.; Giraldi-Díaz, M.R.; De Medina-Salas, L.; De la Cruz, R.V. Environmental Impacts associated to different stages spanning from harvesting to industrialization of pineapple through life cycle assessment. Appl. Sci. 2020, $10,7007$. [CrossRef]

16. Varotsos, C.A.; Tzanis, C. A new tool for the study of the ozone hole dynamics over Antarctica. Atmos. Environ. 2012, 47, 428-434. [CrossRef]

17. Basalirwa, D.; Sudo, S.; Wacal, C.; Namirembe, C.; Sasagawa, D.; Yamamoto, S.; Masunaga, T.; Nishihara, E. Effect of activated carbon on greenhouse gas emissions, seed yield, soil chemical properties and isoflavone content of soybean genotypes with varying nodulation capacities under sandy soil conditions. Rhizosphere 2020, 14, 100202. [CrossRef]

18. Wang, X.; Li, M.; Cai, L.; Li, Y. Propane and iso-butane pre-cooled mixed refrigerant liquefaction process for small-scale skid-mounted natural gas liquefaction. Appl. Energy 2020, 275, 115333. [CrossRef]

19. Mazyan, W.I.; Ahmadi, A.; Ahmed, H.; Hoorfar, M. Increasing the COP of a refrigeration cycle in natural gas liquefaction process using refrigerant blends of Propane- $\mathrm{NH}_{3}$, Propane- $\mathrm{SO}_{2}$ and Propane- $\mathrm{CO}_{2}$. Heliyon 2020, 6, e04750. [CrossRef] [PubMed]

20. Righetti, G.; Zilio, C.; Longo, G.A. Comparative performance analysis of the low GWP refrigerants HFO1234yf, HFO1234ze(E) and HC600a inside a roll-bond evaporator. Int. J. Refrig. 2015, 54, 1-9. [CrossRef]

21. Harby, K. Hydrocarbons and their mixtures as alternatives to environmental unfriendly halogenated refrigerants: An updated overview. Renew. Sustain. Energy Rev. 2017, 73, 1247-1264. [CrossRef]

22. Adelekan, D.S.; Ohunakin, O.S.; Gill, J.; Atiba, O.E.; Okokpujie, I.P.; Atayero, A.A. Performance of a domestic refrigerator infused with safe charge of R600a refrigerant and various concentrations of $\mathrm{TiO}_{2}$ nanolubricants. Procedia Manuf. 2019, 35, 1158-1164. [CrossRef]

23. Pilla, T.S.; Sunkari, P.K.G.; Padmanabhuni, S.L.; Nair, S.S.; Dondapati, R.S. Experimental evaluation mechanical performance of the compressor with mixed refrigerants R-290 and R-600a. Energy Procedia 2017, 109, 113-121. [CrossRef]

24. Sperling, L.; Louwaars, N.; Ponti, O.; Smale, M.; Baributsa, D.; Etten, J. Viewpoint: COVID-19 and seed security response now and beyond. Food Policy 2020, 97, 102000. [CrossRef]

25. Paurine, A.; Maidment, G.G.; Rodway, M.; Yebiyo, M. Understanding the market need for skills in alternative refrigerants with low global warming potential in the EU region-A comprehensive survey on Refrigerant Emissions and Leakage (REAL) alternatives programme. Int. J. Refrig. 2021, 122, 11-20. [CrossRef]

26. Marco-Fondevila, M.; Moneva, J.M.; Llena-Macarulla, F. Accounting for carbon footprint flows in wine production process. Case study in Spanish winery. Appl. Sci. 2020, 10, 8381. [CrossRef]

27. Wróbel-Jędrzejewska, M.; Stęplewska, U.; Włodarczyk, E.; Polak, E. Determination of the emissivity factor under cooling conditions in the agri-food industry. Post. Nauk. Tech. Przem. Rol-Spoż. 2020, 1, 32.

28. Regulation (EU) No 517/2014 of the European Parliament and of the Council of 16 April 2014 on Fluorinated Greenhouse Gases and Repealing Regulation (EC) No 842/2006. Available online: https://eur-lex.europa.eu/legal-content/EN/TXT/PDF/?uri= CELEX:32014R0517\&rid=1 (accessed on 1 February 2021).

29. Heredia-Aricapa, Y.; Belman-Flores, J.M.; Mota-Babiloni, A.; Serrano-Arellano, J.; García-Pabón, J.J. Overview of low GWP mixtures for the replacement of HFC refrigerants: R134a, R404A and R410A. Int. J. Refrig. 2020, 111, 113-123. [CrossRef]

30. Colbourne, D.; Suenb, K.O.; Li, T.-X.; Vince, I.; Vonsil, A. General framework for revising class A3 refrigerant charge limits-A discussion. Int. J. Refrig. 2020, 117, 209-217. [CrossRef]

31. Weather Online. Available online: www.weatheronline.pl (accessed on 1 February 2021). 